\title{
Rationale and design of WEBCARE: A randomized, controlled, web-based behavioral intervention trial in cardioverter-defibrillator patients to reduce anxiety and device concerns and enhance quality of life
}

\author{
Susanne S Pedersen*1,2, Viola Spek1 ${ }^{1}$ Dominic AMJ Theuns ${ }^{2}$, Marco Alings ${ }^{3}$, \\ Pepijn van der Voort ${ }^{4}$, Luc Jordaens ${ }^{2}$, Pim Cuijpers ${ }^{5}$, Johan Denollet ${ }^{1}$ and \\ Krista $C$ van den Broek ${ }^{1}$
}

Address: ${ }^{1}$ CoRPS, Department of Medical Psychology, Tilburg University, Tilburg, the Netherlands, ${ }^{2}$ Department of Cardiology, Thoraxcenter, Erasmus Medical Center, Rotterdam, the Netherlands, ${ }^{3}$ Department of Cardiology, Amphia Hospital, Breda, the Netherlands, ${ }^{4}$ Department of Cardiology, Catharina Hospital, Eindhoven, the Netherlands and ${ }^{5}$ Department of Clinical Psychology, VU University Amsterdam, the Netherlands

Email: Susanne S Pedersen* - s.s.pedersen@uvt.nl; Viola Spek - v.r.m.spek@uvt.nl; Dominic AMJ Theuns - d.theuns@erasmusmc.nl; Marco Alings - marco@alings.org; Pepijn van der Voort - pepijn.vd.voort@catharina-ziekenhuis.nl; Luc Jordaens - l.jordaens@erasmusmc.nl; Pim Cuijpers - P.Cuijpers@psy.vu.nl; Johan Denollet - denollet@uvt.nl; Krista C van den Broek - C.C.L.T.vdnBroek@uvt.nl

* Corresponding author

\section{Published: 23 December 2009}

Trials 2009, 10:120 doi:10.1186/1745-6215-10-120

This article is available from: http://www.trialsjournal.com/content//0/I/I20

(C) 2009 Pedersen et al; licensee BioMed Central Ltd.

This is an Open Access article distributed under the terms of the Creative Commons Attribution License (http://creativecommons.org/licenses/by/2.0), which permits unrestricted use, distribution, and reproduction in any medium, provided the original work is properly cited.
Received: 6 June 2009

Accepted: 23 December 2009

\begin{abstract}
Background: The implantable cardioverter defibrillator (ICD) is generally well accepted, but 25-33\% of patients experience clinical levels of anxiety, depression, and impaired quality of life (QoL) following implantation. Few trials in ICD patients have investigated whether behavioral intervention may mitigate the development of these adjustment problems. We present the rationale and study design of the WEBbased distress management program for implantable CARdioverter dEfibrillator patients (WEBCARE) trial.

Methods: WEBCARE is a multi-center, multi-disciplinary, randomized, controlled behavioral intervention trial designed to examine the effectiveness of a web-based approach in terms of reducing levels of anxiety and device concerns and enhancing QoL. Consecutive patients hospitalized for the implantation of an ICD will be approached for study participation while in hospital and randomized to the intervention arm ( $\mathrm{n}=$ 175) versus usual care $(n=175)$ at baseline $(5-10$ days post implantation). Patients will complete assessments of patient-centered outcomes at baseline, 14, 26, and 52 weeks after implantation. Patients randomized to the intervention arm will receive a 12 -week web-based behavioral intervention starting 2 weeks after implantation. Primary endpoints include $\left(i_{i}\right)$ patient-centered outcomes (i.e., anxiety, depression, ICD acceptance, $Q \mathrm{QL})$; $\left(\mathrm{i}_{\mathrm{iii}}\right)$ health care utilization; and $\left(\mathrm{i}_{\mathrm{iii}}\right)$ cost-effectiveness. All primary endpoints will be assessed with standardized and validated disease-specific or generic questionnaires. Secondary endpoints include $\left(\mathrm{ii}_{\mathrm{i}}\right)$ cortisol awakening response; and $\left(\mathrm{ii}_{\mathrm{ii}}\right)$ ventricular arrhythmias.
\end{abstract}

Discussion: WEBCARE will show whether a behavioral intervention using a web-based approach is feasible and effective in reducing anxiety and ICD concerns and improving QoL in ICD patients.

Trial Registration: http://www.ClinicalTrials.gov. Identifier: NCT00895700. 


\section{Background}

Implantable cardioverter defibrillator (ICD) therapy is considered the treatment of choice for the prevention of sudden cardiac death (SCD) both in patients who have survived life-threatening arrhythmias (secondary prevention) and in patients at risk for these arrhythmias due to coronary artery disease and left ventricular dysfunction (primary prevention) [1]. The number of ICD implantations has risen considerably, since the first ICD was implanted in humans [2-4]. This increase in implantation rates can in part be attributed to expansion of the indications for ICD implantation to also include primary prevention, due to ICD therapy being superior to antiarrhythmic drugs in the prevention of SCD in these highrisk patients [5-7].

Despite the medical benefits of ICD therapy, and the device generally being well accepted by the majority of patients [8], 25-33\% of patients experience clinical levels of anxiety, depression, and impaired quality of life (QoL) following implantation [9-12]. These difficulties may be attributed to actual ICD shocks $[13,14]$, but also to devicerelated concerns including fear of shocks $[15,16]$, ICD advisories (i.e., a notification from ICD manufacturers that the hardware may potentially malfunction) [17], and the psychological make-up of the patient, including lack of optimism [18] and personality factors, such as the distressed (Type D) personality $[11,12,19]$. The prevention of the manifestation of psychological distress in ICD patients is important, given preliminary evidence that distress may increase the risk of ventricular tachyarrhythmias [20-22]. Hypercortisolemia, reflecting a dysregulation of the hypothalamus-pituitary-adrenocortical axis, may provide one of the mechanisms linking psychological factors to ventricular tachyarrythmias due to increased inflammation arising from chronic stress [23].

Preliminary evidence suggests that ICD patients benefit from psychological and behavioral intervention, with the largest effect being found in reductions of symptoms of anxiety and improved exercise capacity [24]. One intervention trial has also found a reduction in cortisol levels [25]. However, the number of large-scale intervention trials in ICD patients is scarce $[24,26]$, with the majority of these trials having used a nurse-based approach, cognitive behavioral therapy as stand-alone therapy, or in combination with cardiac rehabilitation. A web-based intervention may be equally effective and have advantages over these more traditional forms [27]. Advantages of a web-based intervention include its low-threshold accessibility via the internet, which makes it logistically feasible for most patients to participate, as they do not have to take time off work, but can access the intervention at home in their own time. In addition, a web-based approach safeguards the patient's anonymity, and the patient avoids the stigma associated with traditional, face-to-face therapy. Such an approach may be particularly useful for patients with a Type D personality profile, who are at increased risk of adverse health outcomes, as they do not share their emotions in social interactions due to fear of rejection [28].

\section{Design}

The WEB-based distress management program for implantable CARdioverter dEfibrillator patients (WEBCARE) is a Dutch multi-center, multi-disciplinary, randomized, controlled behavioral intervention trial designed to examine the effectiveness and feasibility of a web-based approach in terms of reducing levels of anxiety and device concerns and enhancing QoL in ICD patients. The trial has been registered on http://www.ClinicalTrials.gov (NCT00895700).

\section{Study population and eligibility criteria}

Consecutive patients $(\mathrm{N}=350)$ hospitalized for the implantation of an ICD in three medical centers in The Netherlands will be approached for study participation while in hospital and randomized to the intervention arm $(n=175)$ versus usual care $(n=175)$ at baseline $(5-10$ days post implantation). Patients (i) being implanted with an ICD, (ii) between 18-75 years of age, (iii) speaking and understanding Dutch, (iv) with access to and ability to use the internet, and (v) providing written informed consent will be eligible to participate. Patients with a life expectancy less than 1 year, with a history of psychiatric illness other than affective/anxiety disorders, on the waiting list for heart transplantation, or with insufficient knowledge of the Dutch language will be excluded.

\section{Study procedure, randomization and follow-up}

The study protocol will be approved by the medical ethics committees of the participating centers. The study will be conducted according to the Declaration of Helsinki, as amended in 2008 by the World Medical Association, and all patients will be informed orally and in writing about the purpose, rights, and possible benefits/risks of the study.

Patients will be invited to participate in the study while hospitalized for their ICD implantation. Patients responding positively to the invitation will be given the informed consent form and the baseline questionnaire package. In order to avoid measuring pre-operative stress, patients will be asked to complete the baseline assessment between 5 and 10 days $\left(\mathrm{T}_{0}\right)$ after implantation. If the baseline questionnaire is not returned within 7 days, patients will receive a reminder telephone call. When the signed informed consent form and completed baseline assessments are received at the trial coordinating center, the coordinating center will randomize the patient either to the treatment arm or to usual care. There will be a separate 
randomization list for each participating hospital. The patient will be informed by telephone to which condition he/she has been randomized and the procedure for the rest of the study. If the patient is randomized to the internet intervention, he/she will receive a login and password in order to be able to access the intervention. The day of randomization will be the first day of the intervention period, with the duration of the intervention being 12 weeks. For both study conditions, the follow-up assessments will take place $14\left(\mathrm{~T}_{1}\right), 26\left(\mathrm{~T}_{2}\right)$, and 52 weeks $\left(\mathrm{T}_{3}\right)$ post implantation. All randomized patients, irrespective of condition, will be followed until the scheduled study end. A schematic representation of the study design is shown in Figure 1.

\section{Study endpoints}

Primary endpoints include $\left(\mathrm{i}_{\mathrm{i}}\right)$ patient-centered outcomes (i.e., anxiety, depression, ICD acceptance, QoL); ( $\left.\mathrm{i}_{\mathrm{ii}}\right)$ health care utilization; and $\left(\mathrm{i}_{\text {iii }}\right)$ cost-effectiveness of the intervention. Secondary endpoints include $\left(\mathrm{ii}_{\mathrm{i}}\right.$ ) cortisol awakening response; and $\left(\mathrm{ii}_{\mathrm{ii}}\right)$ ventricular arrhythmias.

\section{Assessment of primary endpoints}

All primary endpoints in addition to psychological factors, such as Type D personality [29], will be assessed with standardized and validated measures shown to have acceptable psychometric properties (Table 1). Diseasespecific measures include the Florida Shock Anxiety Scale [30], the Minnesota Living with Heart Failure question- naire [31], the ICD Patient Concerns questionnaire [16], and the Florida Patient Acceptance Survey [32,33].

\section{Assessment of secondary endpoints}

Salivary cortisol will be assessed, using the Salivette (manufactured by Sarstedt, Etten-Leur, The Netherlands), at 3 out of the 4 time points, corresponding to the assessment of patient-centered outcomes and psychological variables (i.e., $\mathrm{T}_{0}=5$ to 10 days after ICD implantation; $\mathrm{T}_{1}=14$ weeks post-implantation; $T_{3}=52$ weeks post-implantation). Due to test-retest reliability characteristics of cortisol $[34,35]$, samples will be taken on two consecutive weekdays at each time point. Four samples will be taken at each time point and on the consecutive day, that is (a) when waking up, (b) 1/2 hour later, (c) 11.00 a.m., and (d) 3.00 p.m. Samples will be sent to the coordinating trial center, where they will be stored at $-20^{\circ}$ Celsius until assayed.

Information on ventricular arrhythmias will be gathered from the electrograms stored by the ICD that will be reviewed and classified by two experienced electrophysiologists from the EP staff of the participating centers, who are blind to whether patients are assigned to the treatment or usual care arm. In case the two reviewers disagree about the diagnosis, a third one will be consulted to reach a consensus. For each episode, the date, type, and mean cycle length of the tachyarrhythmia will be recorded, as well as the type and outcome of delivered ICD therapy. The

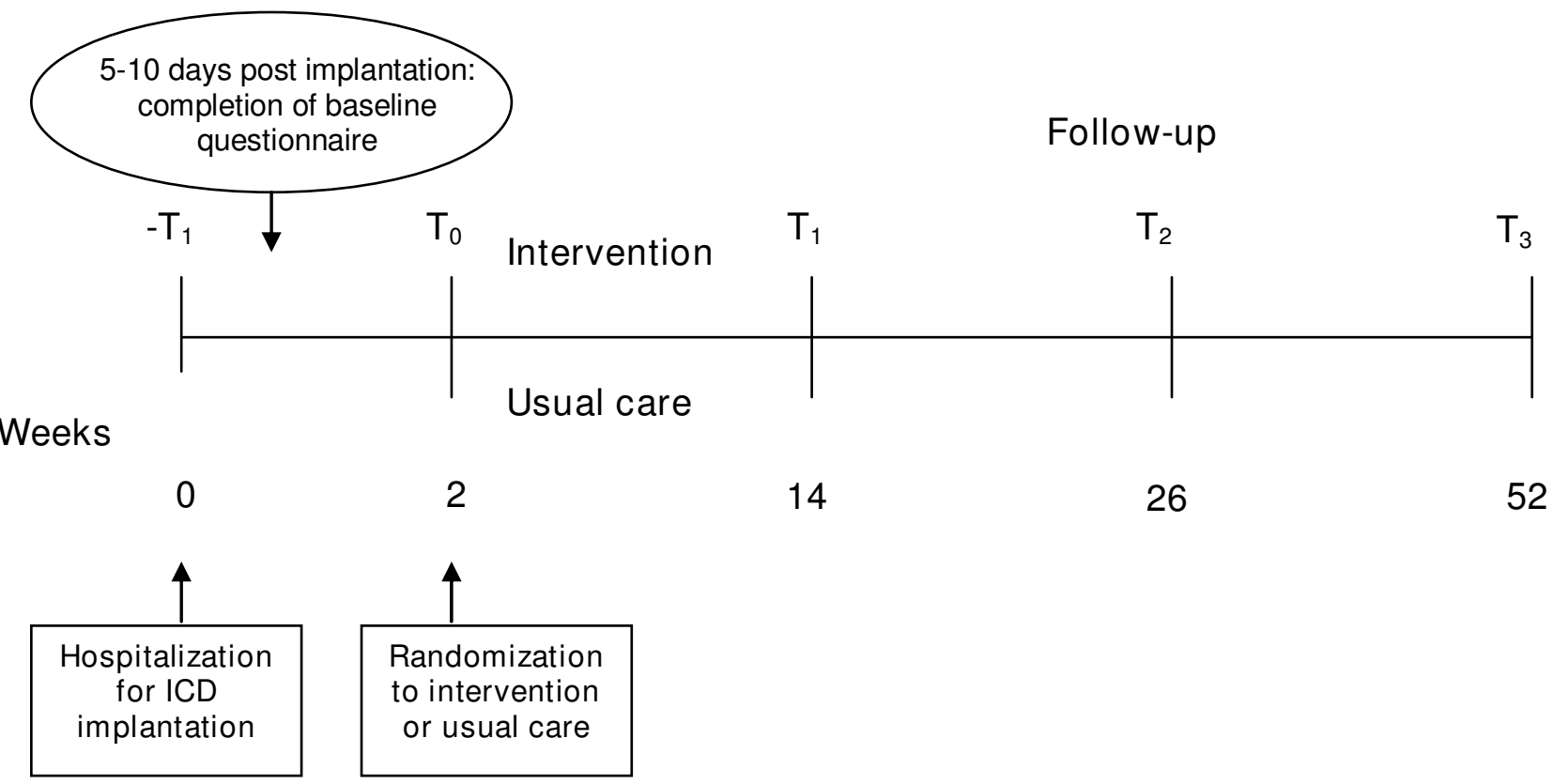

Figure I

Schematic representation of the study procedure. 
Table I: Patient-centered outcomes and psychological factors assessed in the trial

\begin{tabular}{|c|c|c|c|c|c|c|}
\hline Construct & Questionnaire & & $\mathbf{T}_{0}$ & $\mathbf{T}_{\mathbf{1}}$ & $\mathbf{T}_{2}$ & $\mathbf{T}_{3}$ \\
\hline \multirow[t]{4}{*}{ Anxiety } & STAI-S & State Trait Anxiety Inventory (state only) & $\mathbf{x}$ & $\mathbf{x}$ & $\mathbf{x}$ & $\mathbf{x}$ \\
\hline & FSAS & Florida Shock Anxiety Scale & $\mathbf{x}$ & $\mathbf{x}$ & $\mathbf{x}$ & $\mathbf{x}$ \\
\hline & PDS & Posttraumatic Stress Scale & & $\mathbf{x}$ & $\mathbf{x}$ & $\mathbf{x}$ \\
\hline & DAl-4 & Denollet Anxiety Inventory & $\mathbf{x}$ & $x$ & $\mathbf{x}$ & $\mathbf{x}$ \\
\hline \multirow[t]{2}{*}{ Depressive symptoms } & HADS & Hospital Anxiety and Depression Scale & $\mathbf{x}$ & $\mathbf{x}$ & $\mathbf{x}$ & $\mathbf{x}$ \\
\hline & PHQ-9 & Patient Health Questionnaire & $\mathbf{x}$ & $\mathbf{x}$ & $\mathbf{x}$ & $\mathbf{x}$ \\
\hline \multirow[t]{2}{*}{ Quality of life } & SF-12 & Short Form Health Survey 12 & $\mathbf{x}$ & $\mathbf{x}$ & $\mathbf{x}$ & $\mathbf{x}$ \\
\hline & MLWFQ & Minnesota Living With Heart Failure Questionnaire & $\mathbf{x}$ & $\mathbf{x}$ & $\mathbf{x}$ & $\mathbf{x}$ \\
\hline ICD concerns & ICDC & ICD Patient Concerns Questionnaire & $\mathbf{x}$ & $\mathbf{x}$ & $\mathbf{x}$ & $\mathbf{x}$ \\
\hline ICD acceptance & FPAS & Florida Patient Acceptance Survey & $\mathbf{x}$ & $\mathbf{x}$ & $\mathbf{x}$ & $\mathbf{x}$ \\
\hline Health care utilization and cost-effectiveness & TiC-P & $\begin{array}{l}\text { Trimbos/iMTA questionnaire for Costs associated with } \\
\text { Psychiatric Illness }\end{array}$ & $\mathbf{x}$ & & & $\mathbf{x}$ \\
\hline Type D personality & DSI4 & Type D Scale & $\mathbf{x}$ & $\mathbf{x}$ & $\mathbf{x}$ & $\mathbf{x}$ \\
\hline
\end{tabular}

$\mathbf{T}_{0}=$ Baseline; $\mathbf{T}_{1}=14$ weeks; $\mathbf{T}_{2}=26$ weeks; $\mathbf{T}_{3}=52$ weeks.

arrhythmia will be classified as (1) ventricular tachyarrhythmia or (2) atrial tachyarrhythmia without a coexistent ventricular arrhythmia. Therapy triggered by ventricular tachyarrhythmia will be considered as appropriate, while therapy delivered for atrial tachyarrhythmia (including atrial fibrillation, atrial flutter, atrial tachycardia, sinus tachycardia) or $\mathrm{T}$ wave oversensing and noise will be defined as inappropriate

\section{Intervention versus usual care}

Patients randomized to the treatment arm will receive an internet-based intervention starting 2 weeks after implantation. They will receive a username and password to access the intervention via the web. Every week an automated email will be sent to the participants to explain the contents and exercises for the coming week. All the information, as well as the exercise forms, will be downloadable from the website in case participants prefer to read the information on paper. Master's level psychology students, trained and supervised by psychologists will provide feedback on the completed exercises. This feedback is not meant to be therapeutic; it will be directed toward mastering the problem-solving strategies. The maximum amount of time the psychology students should spend on feedback will be 60 minutes per participant. The compo- nents of the intervention are presented in Table 2. The intervention has to be completed within 12 weeks, as we learnt in an earlier trial that one session a week is too fast a pace for most people. A typical session takes about 30 minutes and consists of an introduction, a discussion of the previous lesson's homework, new theory and homework for the subsequent week. The sessions are designed to be followed on a weekly or two-weekly basis. These time indications may vary among users. Besides the sessions, the participants have several resources at their disposal: a homework station, extra information, reading tips, useful links, and addresses for additional help. Patients randomized to the usual care arm will receive care as it is standardly offered to ICD patients in the three centers, comprised of an information booklet about ICD treatment, standard clinical follow-up visits, and home monitoring of the device (if applicable).

\section{Statistical analysis and power calculation}

The trial is designed to show whether a web-based behavioral intervention is effective in improving patient-centered outcomes compared to usual care. The power analysis was performed in relation to anxiety as the primary endpoint, since anxiety is a pertinent outcome measure in ICD patients due to the unique feature of the ICD

Table 2: Components of the I2-week web-based intervention

\begin{tabular}{ll}
\hline Components & Topics dealt with \\
\hline - Psycho-education about the ICD & - Emotional reactions to ICD therapy \\
- Problem-solving skills & - Which aspects of ICD therapy may lead to distress \\
- Cognitive restructuring & - How to deal with shocks \\
- Relaxation training & - Disease-specific issues and fears \\
- Personalized feedback by a therapist via the computer & - How to prevent the avoidance of activities \\
& - Interpretation of bodily symptoms \\
& - How to cope with uncertainty \\
& - Help-seeking behaviour \\
& - How to cope with stress
\end{tabular}


being able to provide a shock. With (i) an expected between group effect size of .30., based on a recent metaanalysis of web-based intervention for symptoms of anxiety and depression [36] and taking into consideration that our population consists partly of patients with subclinical anxiety and depression levels; (ii) alpha $=0.05$; (iii) power $=0.80$ (two-sided test), 350 patients are needed (i.e., 175 in each condition). Although we had a response rate of $82 \%$ in an earlier study $[16,19]$, based on a more conservative response rate of $50 \%, 700$ patients need to be approached.

The effectiveness of the intervention will be examined using the intention-to-treat principle, with the inclusion of all randomized participants in the statistical analysis regardless of whether they completed the intervention or the follow-up measurements. Missing data will be imputed using regression imputation techniques. Univariable and multivariable regression analyses (both linear and Cox proportional hazard regression analysis) and analysis of variance and analysis of covariance with repeated measures will be used to investigate the effect of the intervention on the endpoints. The type of regression analysis will depend on the endpoint in question. Demographic, clinical and psychological variables will be included in multivariable analyses in order to control for their potential confounding effects. A p-value $<0.05$ will be used to indicate statistical significance. All data will be analyzed using SPSS 17.0 for Windows (SPSS Inc., Chicago, Illinois).

\section{Discussion}

The ICD is generally well accepted by patients [8], but 25$33 \%$ of patients experience clinical levels of anxiety, depression, and impaired QoL following implantation [912].

Preliminary evidence suggests that psychological and behavioral intervention may mitigate the development of adjustment problems in ICD patients, but the number of large-scale intervention trials in ICD patients is scarce [2527]. In addition, all of these trials have used a nurse-based approach, cognitive behavioral therapy as stand-alone therapy, or in combination with cardiac rehabilitation. A web-based intervention may be equally effective and have advantages over these more traditional forms [28]. The WEB-based distress management program for implantable CARdioverter dEfibrillator patients (WEBCARE) is a multi-center, multi-disciplinary, randomized, controlled behavioral intervention trial designed to examine whether a web-based approach leads to better patient-centered outcomes, in terms of reduced levels of anxiety and device concerns and improved QoL. The trial aims to include 350 patients from three Dutch centers.

\section{Abbreviations}

ICD: Implantable cardioverter defibrillator; QoL: Quality of life; SCD: Sudden cardiac death.

\section{Competing interests}

The authors declare that they have no competing interests.

\section{Authors' contributions}

SSP in collaboration with VS, JD and KCB designed the study. PC provided the basis for the intervention, which was adapted by SSP, VS and KCB for ICD patients. SSP drafted the manuscript. VS, DT, MA, PV, LJ, PC, JD and KCB revised the manuscript critically. All have given their final approval of the version to be published.

\section{Acknowledgements}

This trial is supported with grant no. 300020002 from ZonMw - The Netherlands Organisation for Health Research and Development, the Hague, The Netherlands. We would like to thank Peter Zaadstra from STIN (Stichting ICD dragers Nederland - Association for Dutch ICD patients) for his willingness to serve as consultant on the trial.

\section{References}

I. Zipes DP, Camm AJ, Borggrefe M, Buxton AE, Chaitman B, Fromer M, Gregoratos G, Klein G, Moss AJ, Myerburg RJ, Priori SG, Quinones MA, Roden DM, Silka MJ, Tracy C, Smith SC Jr, Jacobs AK, Adams CD, Antman EM, Anderson JL, Hunt SA, Halperin JL, Nishimura R, Ornato JP, Page RL, Riegel B, Blanc JJ, Budaj A, Dean V, Deckers JW, Despres C, Dickstein K, Lekakis J, McGregor K, Metra M, Morais J, Osterspey A, Tamargo JL, Zamorano JL, American College of Cardiology/American Heart Association Task Force; European Society of Cardiology Committee for Practice Guidelines; European Heart Rhythm Association; Heart Rhythm Society: ACCIAHA/ESC 2006 Guidelines for Management of Patients With Ventricular Arrhythmias and the Prevention of Sudden Cardiac Death: a report of the American College of Cardiology/American Heart Association Task Force and the European Society of Cardiology Committee for Practice Guidelines (writing committee to develop Guidelines for Management of Patients With Ventricular Arrhythmias and the Prevention of Sudden Cardiac Death): developed in collaboration with the European Heart Rhythm Association and the Heart Rhythm Society. Circulation 2006, I | 4:e385-484.

2. Crespo EM, Kim J, Selzman KA: The use of implantable cardioverter defibrillators for the prevention of sudden cardiac death: a review of the evidence and implications. Am J Med Sci 2005, 329:238-246.

3. Seidl K, Senges ]: Worldwide utilization of implantable cardioverter/defibrillators now and in the future. Card Electrophysiol Rev 2003, 7:5-13.

4. Lloyd-Jones D, Adams R, Carnethon M, De Simone G, Ferguson TB, Flegal K, Ford E, Furie K, Go A, Greenlund K, Haase N, Hailpern S, Ho M, Howard V, Kissela B, Kittner S, Lackland D, Lisabeth L, Marelli A, McDermott M, Meigs J, Mozaffarian D, Nichol G, O'Donnell C, Roger V, Rosamond W, Sacco R, Sorlie P, Stafford R, Steinberger J, Thom T, Wasserthiel-Smoller S, Wong N, Wylie-Rosett J, Hong Y, American Heart Association Statistics Committee and Stroke Statistics Subcommittee: Heart disease and stroke statistics -- 2009 update: a report from the American Heart Association Statistics Committee and Stroke Statistics Subcommittee. Circulation 2009, II9:e2I-el8I.

5. Moss AJ, Zareba W, Hall WJ, Klein H, Wilber DJ, Cannom DS, Daubert JP, Higgins SL, Brown MW, Andrews ML: Prophylactic implantation of a defibrillator in patients with myocardial infarction and reduced ejection fraction. N Engl J Med 2002, 346:877-883.

6. Bristow MR, Saxon LA, Boehmer J, Krueger S, Kass DA, De Marco T, Carson P, DiCarlo L, DeMets D, White BG, DeVries DW, Feldman AM, Comparison of Medical Therapy, Pacing, and Defibrillation in Heart Failure (COMPANION) Investigators: Cardiac-resynchroni- 
zation therapy with or without an implantable defibrillator in advanced chronic heart failure. N Engl J Med 2004, 350:2 140-2150.

7. Bardy GH, Lee KL, Mark DB, Poole JE, Packer DL, Boineau R, Domanski M, Troutman C, Anderson J, Johnson G, McNulty SE, Clapp-Channing N, Davidson-Ray LD, Fraulo ES, Fishbein DP, Luceri RM, Ip JH: Amiodarone or an implantable cardioverter-defibrillator for congestive heart failure. N Engl J Med 2005, 352:225-237.

8. Johansen JB, Pedersen SS, Spindler H, Andersen K, Nielsen JC, Mortensen PT: Symptomatic heart failure is the most important clinical correlate of impaired quality of life, anxiety, and depression in implantable cardioverter-defibrillator patients: a single-centre, cross-sectional study in 610 patients. Europace 2008, 10:545-55I.

9. Bostwick JM, Sola CL: An updated review of implantable cardioverter/defibrillators, induced anxiety, and quality of life. Psychiatr Clin North Am 2007, 30:677-688.

10. Matchett M, Sears SF, Hazelton G, Kirian K, Wilson E, Nekkanti R The implantable cardioverter defibrillator: its history, cur rent psychological impact and future. Expert Rev Med Devices 2009, 6:43-50.

II. Broek KC Van den, Nyklicek I, Van der Voort PH, Alings M, Denollet $\mathrm{J}$ : Shocks, personality, and anxiety in patients with an implantable defibrillator. Pacing Clin Electrophysiol 2008, 3 1:850-857.

12. Pedersen SS, Theuns DA, Muskens-Heemskerk A, Erdman RA, Jordaens L: Type $D$ personality but not implantable cardioverter-defibrillator indication is associated with impaired health-related quality of life 3 months post-implantation. Europace 2007, 9:675-680.

13. Schron EB, Exner DV, Yao Q, Jenkins LS, Steinberg JS, Cook JR, Kutalek SP, Friedman PL, Bubien RS, Page RL, Powell J: Quality of life in the antiarrhythmics versus implantable defibrillators trial: impact of therapy and influence of adverse symptoms and defibrillator shocks. Circulation 2002, 105:589-594.

14. Sears SF Jr, Conti JB: Quality of life and psychological functioning of ICD patients. Heart 2002, 87:488-493.

15. Pedersen SS, Theuns DA, Erdman RA, Jordaens L: Clustering of device-related concerns and type $D$ personality predicts increased distress in ICD patients independent of shocks. Pacing Clin Electrophysiol 2008, 31:20-27.

16. Pedersen SS, van Domburg RT, Theuns DA, Jordaens L, Erdman RA Concerns about the implantable cardioverter defibrillator: a determinant of anxiety and depressive symptoms independent of experienced shocks. Am Heart J 2005, 149:664-669.

I7. Broek KC Van den, Denollet J, Nyklicek I, Voort PH Van der: Psychological reaction to potential malfunctioning of implantable defibrillators. Pacing Clin Electrophysiol 2006, 29:953-956.

18. Sears SF, Lewis TS, Kuhl EA, Conti JB: Predictors of quality of life in patients with implantable cardioverter defibrillators. Psychosomatics 2005, 46:45।-457.

19. Pedersen SS, van Domburg RT, Theuns DA, Jordaens L, Erdman RA: Type $D$ personality is associated with increased anxiety and depressive symptoms in patients with an implantable cardioverter defibrillator and their partners. Psychosom Med 2004 66:7|4-7|9.

20. Whang W, Albert CM, Sears SF Jr, Lampert R, Conti JB, Wang PJ, Singh JP, Ruskin JN, Muller JE, Mittleman MA, TOVA Study Investigators: Depression as a predictor for appropriate shocks among patients with implantable cardioverter-defibrillators: results from the Triggers of Ventricular Arrhythmias (TOVA) study. I Am Coll Cardiol 2005, 45: 1090-1095.

21. Dunbar SB, Kimble LP, Jenkins LS, Hawthorne M, Dudley W, Slemmons $M$, Langberg J]: Association of mood disturbance and arrhythmia events in patients after cardioverter defibrillator implantation. Depress Anxiety 1999, 9:163-168.

22. Lampert R, Joska T, Burg MM, Batsford WP, McPherson CA, Jain D Emotional and physical precipitants of ventricular arrhythmia. Circulation 2002, 106:1800-1805.

23. Weber CS, Thayer JF, Rudat M, Sharma AM, Perschel FH, Buchholz K, Deter HC: Salt-sensitive men show reduced heart rate variability, lower norepinephrine and enhanced cortisol during mental stress. J Hum Hypertens 2008, 22:423-43I.

24. Pedersen SS, Broek KC van den, Sears SF Jr: Psychological intervention following implantation of an implantable defibrilla tor: a review and future recommendations. Pacing Clin Electrophysiol 2007, 30: I546-I554.

25. Sears SF, Sowell LD, Kuhl EA, Kovacs AH, Serber ER, Handberg E, Kneipp SM, Zineh I, Conti JB: The ICD shock and stress management program: a randomized trial of psychosocial treatment to optimize quality of life in ICD patients. Pacing Clin Electrophysiol 2007, 30:858-864

26. Lewin RJ, Coulton S, Frizelle DJ, Kaye G, Cox H: A brief cognitive behavioural preimplantation and rehabilitation programme for patients receiving an implantable cardioverter-defibrillator improves physical health and reduces psychological morbidity and unplanned readmissions. Heart 2009, 95:63-69.

27. Kuhl EA, Sears SF, Vazques LD, Conti JB: Patient-assisted computerized education for recipients of implantable cardioverter defibrillators: a randomized controlled trial of the PACER program. J Cardiovasc Nurs 2009, 24:225-23I.

28. Pedersen SS, Denollet J: Is Type D personality here to stay? Emerging evidence across cardiovascular disease patient groups. Curr Cardiol Rev 2006, 2:205-213.

29. Denollet J: DS I 4: standard assessment of negative affectivity, social inhibition, and Type D personality. Psychosom Med 2005, 67:89-97.

30. Kuhl EA, Dixit NK, Walker RL, Conti JB, Sears SF: Measurement of patient fears about implantable cardioverter defibrillator shock: an initial evaluation of the Florida Shock Anxiety Scale. Pacing Clin Electrophysiol 2006, 29:6|4-6I8.

31. Rector TS, Kubo SH, Cohn JN: Patient's self-assessment of their congestive heart failure. Content, reliability, and validity of a new measure: the Minnesota Living with Heart Failure Questionnaire. Heart Failure 1987, 10:198-209.

32. Burns JL, Serber ER, Keim S, Sears SF: Measuring patient acceptance of implantable cardiac device therapy: initial psychometric investigation of the Florida Patient Acceptance Survey. I Cardiovasc Electrophysiol 2005, I 6:384-390.

33. Pedersen SS, Spindler H, Johansen JB, Mortensen PT, Sears SF: Correlates of patient acceptance of the cardioverter defibrillator: cross-validation of the Florida Patient Acceptance Survey in Danish patients. Pacing Clin Electrophysiol 2008, 3I:II68-II77.

34. Hellhammer J, Fries E, Schweisthal OW, Schlotz W, Stone AA, Hagemann D: Several daily measurements are necessary to reliably assess the cortisol rise after awakening: state- and trait components. Psychoneuroendocrinology 2007, 32:80-86.

35. Kraemer HC, Giese-Davis J, Yutsis M, O'Hara R, Neri E, GallagherThompson D, Taylor CB, Spiegel D: Design decisions to optimize reliability of daytime cortisol slopes in an older population. Am J Geriatr Psychiatry 2006, I 4:325-333.

36. Spek V, Cuijpers P, Nyklicek I, Riper H, Keyzer J, Pop V: Internetbased cognitive behaviour therapy for symptoms of depression and anxiety: a meta-analysis. Psychol Med 2007, 37:319-328.

Publish with Bio Med Central and every scientist can read your work free of charge

"BioMed Central will be the most significant development for disseminating the results of biomedical research in our lifetime. "

Sir Paul Nurse, Cancer Research UK

Your research papers will be:

- available free of charge to the entire biomedical community

- peer reviewed and published immediately upon acceptance

- cited in PubMed and archived on PubMed Central

- yours - you keep the copyright 